\title{
A rare case of extralobar sequestration with hemoptysis
}

\author{
Yukio Sato, MD, PhD, Shunsuke Endo, MD, PhD, Noriko Saito, MD, Shinichi Otani, MD, Tsuyoshi Hasegawa, MD, and \\ Yasunori Sohara, MD, PhD, Tochigi, Japan
}

$\mathrm{P}$

ulmonary sequestration is an uncommon type of foregut malformation characterized by nonfunctioning abnormal pulmonary parenchyma that has no connection with the tracheobronchial airway and receives its blood supply from a systemic artery. ${ }^{1}$ Two different forms have been described: intralobar sequestration is localized within the normal pulmonary parenchyma, whereas extralobar sequestration is totally separate from the lung and has a distinct pleural covering. Extralobar sequestration has no communication with the airway, and the chance of it becoming symptomatic in adults is very small. We present herein a case of extralobar sequestration that caused hemoptysis.

\section{Clinical Summary}

A 46-year-old woman, previously in good health, was admitted to our hospital because of a 2-week history of recurrent hemoptysis. No abnormalities were detected on chest roentgenography. Chest computed tomographic scanning (Figure 1) revealed a plate-like consolidation behind the right lower lobe and a string-like structure between the consolidation and the descending aorta, which were suspected as a pulmonary sequestration and an aberrant artery. Angiography revealed an aberrant artery branching from the descending aorta and draining vein to the azygos system (Figure 2). The pulmonary artery of the right lower lobe was simultaneously stained, indicating blood flow not only to the sequestered segment but also to the right lower lobe. An intralobar sequestration was suspected because the aberrant artery also supplied the normal lung. The patient underwent video-assisted thoracoscopic surgery (VATS) with 3 ports. VATS exploration revealed a $5 \times 5 \times 1-\mathrm{cm}$ lung tissue behind the right lower lobe in the paravertebral area. It had a distinct pleural covering and no anthracosis. There was no adhesion or pleural effusion. The aberrant artery emerged from between the vertebra and esophagus, and the vein drained into the azygos system. The lesion was diagnosed as an extralobar sequestration. However, the sequestered lung was connected to the right lower lobe through a narrow (2 mm diameter) strand of tissue containing small vessels. The aberrant artery and draining vein were ligated and divided. The tissue-strand

\footnotetext{
From the Division of Thoracic Surgery, Department of Surgery, Jichi Medical School, Minamikawachi, Tochigi, Japan.

Received for publication Feb 12, 2004; accepted for publication March 4, 2004.

Address for reprints: Yukio Sato, MD, PhD, Division of Thoracic Surgery, Department of Surgery, Jichi Medical School, 3311-1 Minamikawachi, Kawachi, Tochigi 329-0498, Japan (E-mail: tcvysato@jichi.ac.jp).

J Thorac Cardiovasc Surg 2004;128:778-9

$0022-5223 / \$ 30.00$

Copyright (C) 2004 by The American Association for Thoracic Surgery

doi:10.1016/j.jtcvs.2004.03.004
}

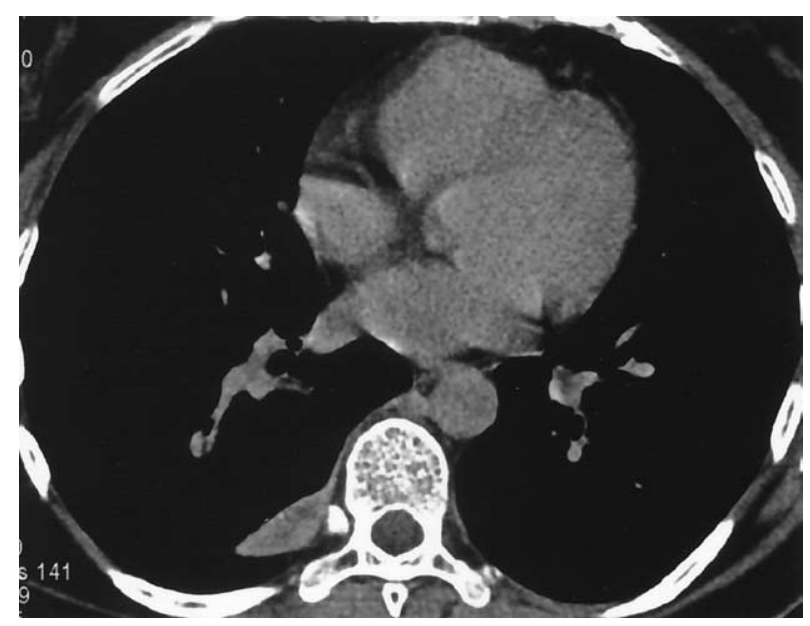

Figure 1. Chest computed tomographic scan showing a plate-like consolidation behind the right lower lobe and string-like structure between the consolidation and the descending aorta. These findings suggest a pulmonary sequestration and an aberrant artery.

attachment site on the right lower lobe was resected with an endothoracic linear cutting device. Thus the sequestered lung was removed with the strand and part of the right lower lobe (Figure 3). The patient recovered uneventfully and was discharged on postoperative day 5 . She remains asymptomatic without hemoptysis 1 year after the operation.

\section{Discussion}

Extralobar sequestration is usually discovered in infancy because it is frequently associated with other congenital anomalies and it causes respiratory distress. ${ }^{1}$ Extralobar sequestration in adults is usually asymptomatic and is found incidentally on routine chest roentgenograms because it is enveloped in its own pleural sac and has no communication with the airway. ${ }^{2}$ There are only a few reports of symptomatic extralobar sequestration in adults. To our knowledge, hemothorax ${ }^{3}$ and infarction ${ }^{4}$ are the only reported symptoms. In our case the patient had no other congenital anomalies and no symptoms before the hemoptysis. This extralobar sequestration was unique because of its connection to normal lung. It is difficult to determine whether the connection between the sequestered lung and the right lower lobe was congenital or acquired as a result of an inflammatory process. However, we suspect that the connection was congenital because VATS findings showed no adhesion or pleural effusion, which would have resulted from inflammation. Flow pressure was probably higher in the sequestered lung than in the normal lung because the aberrant artery feeding the sequestered segment branched off the descending aorta. Therefore we suspect that the blood flowed from the 


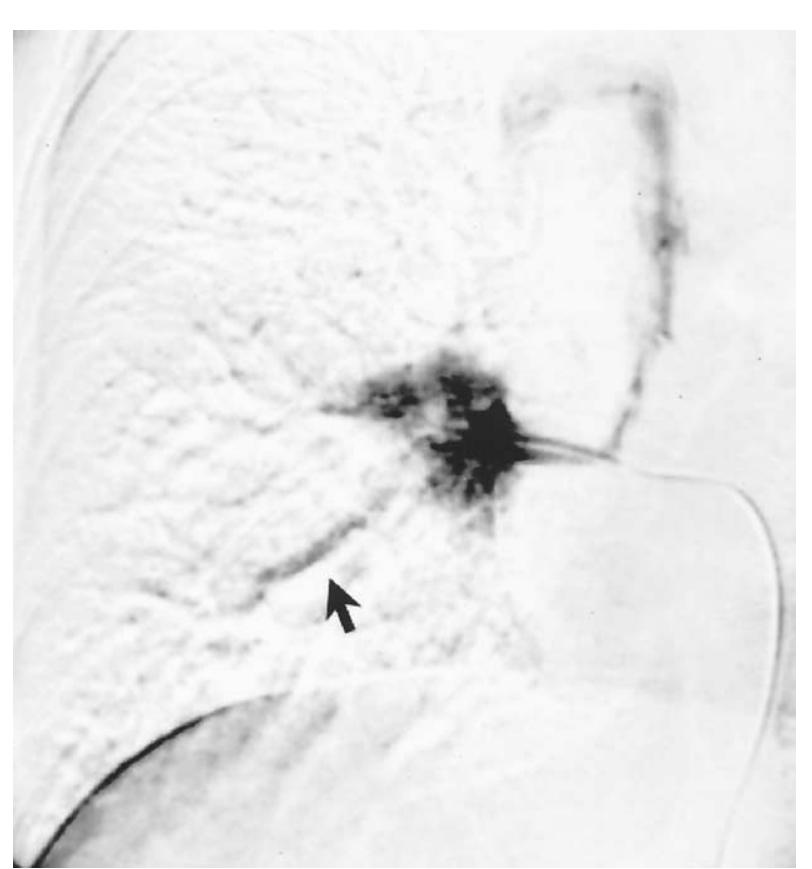

Figure 2. Superselective angiogram from the aberrant artery branching directly from the descending aorta showing staining in the sequestered lung and draining vein into the azygos system. The simultaneous staining of the pulmonary artery in the right lower lobe indicates blood flow from the sequestered segment to the right lower lobe.

sequestered lung into the right lower lobe through a small vessel in the strand of tissue and thereby caused the hemoptysis.

VATS is used to treat a variety of thoracic diseases, including pulmonary sequestration. ${ }^{5}$ In this case VATS was selected and safely performed because preoperative examination, enhanced computed tomography, and angiography precisely identified the aberrant artery and the draining vein of the sequestered lung.

In summary, we treated a rare case of hemoptysis caused by extralobar sequestration in an adult. Presumptive diagnosis enabled safe and minimally invasive treatment with VATS.

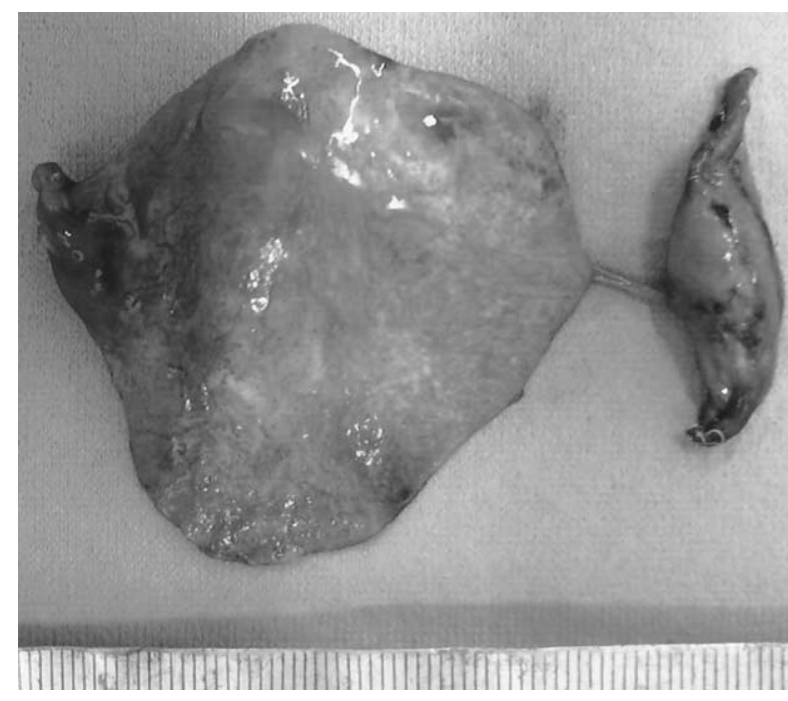

Figure 3. Resected specimen. The sequestered lung (left) and part of the right lower lobe (right) are connected with a strand of tissue containing a small vessel.

\section{References}

1. Savic B, Birtel FJ, Tholen W, Funke HD, Knoche R. Lung sequestration: report of seven cases and review of 540 published cases. Thorax. 1979;34(1):96-101.

2. Carrasco R, Castanon M, San Vicente B, Tarrado X, Montaner A, Morales L. Extralobar infradiaphragmatic pulmonary sequestration with a digestive communication. J Thorac Cardiovas Surg. 2002;123(1): 188-9.

3. Avishai V, Dolev E, Weissberg D, Zajdel L, Priel IE. Extralobar sequestration presenting as massive hemothorax. Chest. 1996;109(3): 843-5.

4. Maull KI, McElvein RB. Infarcted extralobar pulmonary sequestration. Chest. 1975;68(1):98-9.

5. Klena JW, Danek SJ, Bostwick TK, Romero M, Johnson JA. Videoassisted thoracoscopic resection for intralobar pulmonary sequestration: single modality treatment with video-assisted thoracic surgery. J Thorac Cardiovasc Surg. 2003;126(3):857-9. 